Simultaneity of learning orientations in a marketing agency

Juani Swart, Nick Kinnie and Mark Lund

All at the Work and Employment Research Centre (WERC)

School of Management

University of Bath

J.A.Swart@bath.ac.uk

N.J.Kinnie@bath.ac.uk

Mn8mifl@bath.ac.uk

Paper submitted to: 2006 OLKC (Organizational Learning, Knowledge and Capabilities) Conference, University of Warwick, Coventry, UK, 20 - 22 March. 


\title{
Simultaneity of learning orientations in a marketing agency
}

\begin{abstract}
This paper draws on a case study of a marketing agency to illustrate how organizational learning takes place between key groups of knowledge workers both inside and outside the firm. It demonstrates how various knowledge stocks interact in order to create intellectual capital that is valued by clients. The dynamic internal and external environments mean that the simultaneous exploiting of existing knowledge stocks as well as exploring or developing of new knowledge capabilities become critical. These two modes of learning (March, 1991) can take place in two distinct time frames: the planned, longer-term and the accelerated, shorter-term. The ability to switch between these is critical to organizational success in a fast moving, unpredictable environment.
\end{abstract}




\section{Simultaneity of learning orientations in a marketing agency}

\section{Introduction}

Increased competitive pressure and the need to continuously adapt make the conversion of employees' human capital into intellectual capital a strategic imperative for Professional Services Firms (Morris, 2000). Fast moving, uncertain environments mean that the speed of this transformation is vital to success. This places a premium on the ability of organizations to learn quickly how to cope with changing client demands and unpredictable markets as well as plan for longer-term renewal of strategic assets (Crossan et al, 1999).

Our approach to organizational learning is theoretically situated within the knowledge-based perspective (Grant, 1996) and we define organizational learning as the renewal and refinement of strategic knowledge assets. In our analysis we pay attention to both knowledge stocks (human, relational and organizational) and knowledge flows (the interaction between the stocks of knowledge). This enables us to make a contribution to the empirical foundation of organizational learning in three distinct ways: firstly, we take into account a wide variety of strategic knowledge assets at the individual, organizational and relational levels when framing the learning process. Secondly, our focus on the interaction between the knowledge stocks allow us to gain insight into the dynamic nature of the learning processes. Finally, we recognize the duality of learning (renewal/explore and refinement/exploit) as coexistent and temporally framed. This enables us to contribute to the literature on the much neglected aspect of 'time’ in organization studies (Clark, 1985; 1990)

We draw on a detailed case study of a marketing agency (MA) and illustrate how intellectual capital, which takes the form of creative outputs for clients (Alvesson, 2000) is created through the interactions between groups inside and across organizations. MA illustrates the importance and existence of the various temporal frames particularly well because it often has to respond to clients' requests at very short notice: indeed it derives significant competitive advantage from its ability to learn and adapt quickly. Concurrently it needs to plan for the future renewal or development of its strategic knowledge assets. The inclusion of temporal frames is an important aspect of the case study given that 'time' is a dimension which is often 
absent from much of the empirical research in organization studies and organizational learning in particular (Antonacopoulou and Tsoukas, 2002; Butler, 1995; Woolgar, 1988).

In the central section of this paper we examine organizational learning in two temporal frames: the account management process where the need for organizational learning is more planned or longer-term and the short term, responsive process where organizational learning is accelerated to meet clients' needs. This is followed by a discussion of the case and consideration of the implications of our findings. Before this we outline the relevant previous research and explain our research methods.

\section{Previous Research}

Professional service firms depend principally on the knowledge of their human capital to develop and deliver solutions to clients' problems. Organizational learning is critical to these firms because it governs their ability to create and renew these strategic knowledge assets. Ideally this knowledge will lead to the creation of intellectual capital which attracts a premium in the marketplace. The problems set by their clients will vary: some will resemble previous problems whereas others will require highly customised solutions often tailored to highly specific problems (Alvesson, 2000).

The importance of learning comes into focus when we adopt a knowledge-based perspective of the professional services firm (Grant, 1996). This allows us to look beyond the very valuable individual level knowledge and skills (human capital) to take into account a variety of knowledge assets within the firm. We view knowledge as a valuable resource that is unique, or difficult to imitate, and that has the ability to generate new value which is captured as rents by the firm (Barney, 1991). These strategic assets would be embodied in people and relationships as well as embedded in organizational tacit and explicit routines (Ambrosini and Bowman, 2001).

Given the professional services firms’ knowledge-portfolio it would be important to refine existing knowledge assets. Current expert skills may need to be deepened (Crossan, 1999), current relationships maintained or organizational routines may be refined through continuous enactment. However, the professional services firm often 
depends on the creation of renewed value in the form of alternative service or product offerings. What is of critical importance here is that the firm needs to balance both the refinement and the renewal of its knowledge assets within any particular time period. We define organizational learning as the renewal and refinement of strategic knowledge assets which is enabled through the interaction or flow between key knowledge stocks. Both modes of learning take place concurrently within accelerated/short-term and planned/longer-term time frames.

Long-term success therefore requires organizations and managers to become ambidextrous, capable of bringing about incremental and revolutionary change (Tushman and O’Reilly III, 1996, 2004). The concept of explorative and exploitive modes of organizational learning is central to ambidextrous organizations (March, 1991) and is a key source of competitive advantage. Crossan et al (1989:522) argue that organizational learning should be seen as the principal means of organizational renewal which 'requires that organizations explore and learn new ways while concurrently exploiting what they already have.' The model suggests that firms: (1) explore new learning opportunities outside their current knowledge domains through a process of 'search, variation, risk taking, experimentation, play, flexibility, discovery and innovation' (March, 1991: 71); whilst simultaneously (2) exploiting and deepening existing knowledge stocks through a process of 'refinement, choice, production, efficiency, selection, implementation and execution' (March, 1991: 71). Exploration involves the pursuit of learning outside a firm's current knowledge domains, whereas exploitation involves the refining and deepening of a firm's existing knowledge stocks.

March argues that both strategies are competing for resources that are scarce, and 'as a result, organizations make explicit and implicit choices between the two' (March, 1991:71). The pursuit of either form of learning becomes a strategic choice for firms, governed by explicit criteria (possible alternative investments and competitive strategies) and implicit criteria (the distribution of resources, risk preferences, search rules and practices, firm goals, and inventive procedures), the latter of which is embedded in organizational forms and customs (March, 1991). This is not to say that organizations have to explicitly choose between the two. Rather, as He and Wong (2004) highlight, ambidextrous organizations need to achieve the correct balance if 
they are to improve organizational performance. It has to be noted though that particular tensions exist between these two forms of learning; continuous explorative learning may make it difficult for a firm to embed and refine the existing knowledgebase whereas a predominantly exploitive learning orientation may discourage the use and development of alternative or 'new' forms of knowledge.

Kang and Snell (2004) argue, however, that organizations are able to pursue both exploratory and exploitive learning simultaneously in what they refer to as bilateral learning. Bilateral learning distinguishes itself from the standard approach to learning in ambidextrous organizations, which involves ‘structural ambidexterity' or temporal partitioning. Structural ambidexterity (Adler et al., 1999; Edmondson, 2002; Benner and Tushman, 2003) leads to the creation of separate units in which individuals either explore or exploit, or a variation on this, such as bringing individuals into crossfunctional teams for short periods of time (Birkinshaw and Gibson, 2004). Alternately, temporal partitioning (Hay and Pisano, 1994; Brown and Eisenhardt, 1997) results in firms switching back and forth between explorative and exploitative learning. However, partitioning brings with it issues of: (1) internal conflict; (2) excessive switching costs; and (3) the risk of being "stuck in the middle” (Adler et al., 1999). Bilateral learning, on the other hand, is based on the idea that within a single learning unit, individuals (and groups) can combine both exploitive and explorative learning activities to create new opportunities and re-configure existing ones simultaneously (Nonaka and Takeuchi, 1995; Evan et al., 2002; Gibson and Birkinshaw, 2004). Kang and Snell (2004) frame this learning process in terms of a firm's intellectual capital architecture, which represents its unique configuration of human, social and organizational capital stocks.

Having established the importance of the need to balance exploratory and exploitive learning we need to look more closely at the essential components of organizational learning. Morris and Snell (2005) argue that organizational learning depends on both knowledge stocks and knowledge flows. We develop this by using a theoretical framework to examine the way different forms of capital interact to generate this intellectual capital (Swart, 2004; Swart et al, 2003) (See Figure 1). 
An organization relies on various inputs to renew or refine existing knowledge or strategic assets to create intellectual capital (Morris, 2000). Firstly, organizational learning takes place at the individual level where the organization relies on the knowledge, skills and experience of employees to either refine or renew their own knowledge. Human capital sits at the heart of this individual level organizational learning process. Social capital refers to the value created by leveraging knowledge that is embedded within social networks and interrelationships and created through interactions between individuals and social groups in organizations (Nahapiet and Ghoshal, 1998). Organizational capital refers to knowledge that is institutionalised, codified and then leveraged through organizational structures, systems, processes, databases, manuals and patents (Youndt et al, 2004). Here, we sub-divide this construct into organizational capital (an organization's embedded routines, processes and technologies) and structural capital (the organization of work that facilitates the creation of social capital). Finally, client and network capital, which is viewed as a sub-set of social capital, refers to knowledge that is acquired from clients and wider networks external to the firm, which are then embedded back into the organization (Swart et al, 2003; Swart, 2004).

It is not just the stocks of this capital which are important but the ways in which these forms of capital interact to produce a mix of exploitive and exploratory learning. In particular, the flows of knowledge are central to organizational learning. Subramaniam and Youndt (2005) highlight how organizational capital, positively influenced by social capital has a positive effect on incremental innovative capability, whilst the interaction between human and social capital positively influences radical innovative capability. Without social capital, human capital was: 'negatively associated with radical innovative capability’ (Subramaniam and Youndt, 2005:450). Such interactions have an important role at the organizational, group and individual level on organizational learning, HR systems and in coping with organizational change.

The discussion of knowledge stocks and flows is important, but needs to be developed further to take account of the time dimension (Clark, 1985, 1990; Antonacopoulou and Tsoukas, 2002; Butler, 1995; Woolgar, 1988). In many organizations the ability to learn quickly and effectively is a decisive source of competitive advantage. It is 
not only their ability to create intellectual capital which is important but also their ability to respond to the needs of clients in a timely fashion. Often employees have to develop new intellectual capital in very time-pressured environments. If they can respond and adapt to client requests on time they can often gain an advantage over other potential providers of these services in the market. This ability to create and renew knowledge by learning quickly means that both the stocks and especially the flows of knowledge are central to firms’ success.

It is essential therefore to consider both the stocks of capital, often based heavily on human capital, and the speed at which knowledge flows through the organization because both of these affect the pace of organizational learning. We refer to this as the evolution of learning and seek to understand the key processes involved. We recognise two temporal frames of organizational learning in the firm:

o Account management/longer-term process - which is the organisation's planned process of managing a client over an extended period of time.

o Accelerated/shorter-term process - in which the firm has to respond to client requests in an immediate or fast-paced manner (one or more days).

\section{Background to the case and research methods}

The paper focuses on MA, a fast-growing marketing agency based in the UK. This case illustrates very well the interactions between forms of capital but also because it reflects an organization witnessing evolutionary change of its underlying dynamics. The effectiveness of MA depends critically on its ability to convert the knowledge, skills and expertise of its staff into intellectual capital. This requires the creation of new kinds of knowledge in a fast paced, highly unpredictable environment where time scales are limited and the demands of key clients are likely to change at short notice. Organizational learning involves a sophisticated and changing mix of both exploitation and exploration working with a series of internal parties and important external parties.

The agency, which has its principal offices in London with smaller offices in Manchester in the UK and in New York City, was founded in 1999 by 4 people who felt limited by the opportunities in their existing agency. They set up with venture capital backing, taking with them a major client with whom one of the founders had 
been working. All four people now occupy senior positions in MA. The firm has been very successful and it has grown quickly so that it now employs around 160 people ${ }^{1}$.

There are two main groups of employees: those engaged in managing relations with clients, referred to as the account handlers (AHs) and those whose task is mainly to provide creative output such as art work or written copy (the Creatives). Each of these groups is organised into teams headed by more senior managers and there are five $\mathrm{AH}$ teams and six creative teams. MA is currently working for around 16 clients on a variety of projects including mobile telephones, media companies and public sector organizations.

The case study is part of a wider study of professional service firms being conducted in the US and the UK sponsored by the Chartered Institute of Personnel and Development in the UK which adopts a multi-level, multi-national and multi-method approach to addressing the links between organizational learning and HRM from an intellectual capital viewpoint. The study combines both qualitative and quantitative data from law firms, management consultancies, software and marketing agencies. Our method involves: interviews with senior managers; observation of a series of key meetings in the creative process; interviews with members of the teams involved in the creative process and collection of data from a web based survey. In MA we also had access to an internal employee attitude survey conducted in November 2004.

\section{Learning processes in MA}

We draw on previous research to investigate the process of organizational learning in MA by analysing both the stocks and flows of knowledge (see Table 1). The speed of change and unpredictability of the environment faced by MA provides clear illustrations of the importance especially of the pace of knowledge flow within the organization.

\footnotetext{
${ }^{1}$ Approximately 50 of these are AHs, 50 of these are Creatives, while 20 are senior managers and 40 are administrators and support staff.
} 
MA's intellectual output is typically some form of marketing materials such as posters, leaflets and various kinds of sales promotion devices. This output is produced after a complex series of interactions between the Creatives, the AHs and the relevant group of client representatives. In MA exploiting learning involves adapting existing sales promotional material from one product to another. Exploratory learning leads to innovative work either within client guidelines or drawing on original research which MA conducts. This research is an important part of the new business development programme and becomes a shared resource within MA.

We will look first at a key client interface process used to take a client request through to the delivery of a solution. This process is known as the account management process and it represents the planned/longer-term frame within which organisational learning takes place. It is a key business process with planned phases that stretch across a linear time frame. Thereafter we describe the more accelerated/shorter-term process within which organisational learning takes place. The accelerated process requires fast responses to client demands which means that the account management process need to be malleable to deliver innovative solutions. These two processes require a different stocks and flows of knowledge and organizational learning.

\section{The planned/longer-term process: Account Management}

We can identify four stages in this process.

- Winning the business

- Establishing the account

- Working with the client

- Delivering to the client

The management of an account evolves through these stages in these kinds of organizations and involves relatively predictable organizational learning. MA staff will be involved with a whole series of projects all at different stages, pitching for new business, starting a campaign for a new client and delivering solutions for another. For example an $\mathrm{AH}$ may be responsible for as many as eight different projects - some of them for different clients - all at the same time. Similarly, creative staff may be working on a point of sale campaign for an alcoholic drink, some posters 
for an oil company and direct marketing materials for a mobile phone company simultaneously.

\section{Winning the business}

New clients can be gained in two ways - by means of a competitive tendering process or by being invited to put forward a new proposal without competition ${ }^{2}$. These routes will involve MA preparing a proposal, or 'pitch' to put to a prospective client. The preparation of a 'pitch' involves a period of intense interaction between two groups internal to MA with relatively limited contact with the client at this stage.

Preparing the pitch requires both the Creatives and the AHs to exploit their existing knowledge from similar clients or from clients where knowledge can be transferred to improve their chances of success. For example, knowledge of the consumer behaviour in the mobile phone market may be transferable to promoting alcoholic drinks. Information about the client will be sought from internal past records and from external sources including the internet. New knowledge will also be developed by exploratory learning to create new solutions. This draws on the proprietary research which MA conducts into different markets and consumer groups in which it is seeking to build up expertise.

MA's stock of human capital is therefore absolutely vital in this process. Often the most senior and experienced directors in the firm, including the Managing Director, will be involved in pitches which are for major clients and large accounts. The bidding team has a difficult task because, as Alvesson (1994:545) has argued, its presentation will be made to a client whose team usually includes people who consider themselves to be marketing experts. This pitch work will often be done against very tight time constraints, sometimes less than a week, involving long working hours. It is absolutely essential that the bid team work closely together leading to the effective flow of knowledge if the bid is to be successful. Existing social capital, especially the values of MA, which stress a willingness to give and receive constructive criticism, will be important, ideally allowing newly formed teams to become efficient very quickly. The pitch itself will involve plans for the work on

\footnotetext{
${ }^{2}$ New business can also come from existing clients either by invitation from the client or a proactive proposal from MA.
} 
offer together with practical examples of MA's previous work such as sales promotions, art work or copy to show the client. These examples of intellectual capital are especially important in an industry with few institutional indicators of professional expertise (Alvesson, 1994:545).

Members of the bid team not only have to develop knowledge of the client and its products but they must also put together a persuasive case which requires creative, technical and selling expertise. Structural capital becomes important here as it is essential that the bid team is carefully put together so that the human capital includes people who are good at this variety of activities. Some clients will be influenced by the personal characteristics and reputation of key members of the bid team: human capital is being highly personalised in this case.

\section{Establishing the account}

Once MA have acquired the work they have to establish the teams that will be working on the account and begin to learn about the client ${ }^{3}$. The structural capital now changes because the client becomes key to a triangle of relations spanning the organizational boundaries also involving the Creatives and the AHs. Senior managers in both the client and MA have to decide who will be part of their respective teams. These decisions will be delicate if smooth working relationships are to be established. The client will also sometimes take an interest in the composition of MA's team, especially if they have been persuaded partly by the expertise of individual members of staff in the pitch. They will hope and sometimes expect that these star performers in the bid team will be retained in the account team (Kinnie and Parsons, 2004).

Human and structural capital concerns also loom large for MA when staff are allocated to a new client. Careful judgements will be made, especially by the Creative Director about the competence, suitability and experience of members of staff and, critically, their ability to work together in ways which facilitate the effective flow of knowledge. He will pay close attention to the requirements of the client and the account, but will also bear in mind staff availability and the requirements of other

\footnotetext{
${ }^{3}$ On the AH side typically an account will be headed up by an Account Director or a Group Account Director if it is a large client. There will then be a series of Account Managers and then Account Executives working in the team.
} 
clients. These decisions have been made even more intense in MA because of the speed at which they have gathered new clients since their formation. Around half of the creative staff have only been with MA for a year making it more difficult to form a judgement about their suitability.

Once the teams have been established on both sides there are a series of meetings with the client. At this stage the human capital of the client is dominant because they know much more about their customers and markets than MA. The client have to devise ways of ensuring that their knowledge is transfrred to MA ${ }^{4}$. Indeed, the success of the account is likely to be affected by the ability and willingness of the client to share both the explicit and tacit knowledge they have about their products or service.

The first interaction will usually involve the client giving some feedback to MA explaining why it has won the business. This will be followed by a series of meetings to explain the background to the account as well as the client's aims and objectives. This may be supplemented by allowing members of MA to trial the client's products or services, or to go on site visits to improve their collective knowledge. Members of the MA team build up their human and client capital by examining past marketing activities and they begin to get an understanding of the sound and feel of the brand.

In the words of one Account Manager in the early weeks of working with a new client, '(The client) are new to us and we are still trying to get a steer from them. We're challenging them - the previous agency had a set way of doing things. They are learning with us. It's all new to us, we are getting a feel for their preferences, we are exploring routes.' The Creatives especially are exploring the field and building up their understanding of the product; often they will be helped by accounts they have previously worked on and they will try to exploit this previous knowledge. There is often uncertainty at this stage as one Account Manager said, 'we are not sure if they want us to change things or just push what we've got.' However, a key aspect of MA's staffing approach, as we discuss below, is to avoid creative staff spending too long on one account or sector so that they maintain a freshness of approach.

\footnotetext{
${ }^{4}$ In some instances the client will be strongly influenced by the advertising agency working for them who may provide the basic brand messages which MA's work will have to complement.
} 


\section{Working with the client}

After the initial learning period the relationships and structures evolve further as the members of the team settle down to working on specific campaigns. The structural capital develops between the AHs and Creatives in MA and with the clients' representatives and flows of knowledge become established. The AHs will take over responsibility for managing the relations between the client and the Creatives. They will begin to regularise their relationships by meeting the client face-to-face and developing social capital as the representatives get to know one another.

The AHs will receive a briefing from the client over forthcoming campaigns including details of key deadlines and the available budget. The AHs, not the Creatives, will produce an initial response, perhaps with a long list of suggestions. These will be discussed with the client and then narrowed down into a short list of ideas worth pursuing. At this stage the AHs will produce the Creative Brief which is a key piece of organizational capital. This short (two page) document captures all the key information concerning the objectives, desired outcomes, timescale and budget of the campaign. The human capital of the AHs is absolutely key here: if they get the Creative Brief wrong then no matter what the Creatives do they are unlikely to produce a successful outcome for the client.

Once the Creative Brief has been written it will be 'briefed' into the creative team usually involving an informal presentation supported by stimuli followed by questions and answers during which the parties interrogate the brief together. Here is the opportunity for learning between the two teams working for the client. The aim is to develop an inter-subjective understanding because this is critical to the effective flow of knowledge. In a time-critical environment, where the client message has to be adequately transferred between $\mathrm{AH}$ and the Creatives, the main focus is on accurately and efficiently communicating the core message through standardising and restricting the content of the message, avoiding misinterpretation (Rosness, 2004). This is partly accomplished through the Creative Brief. At the micro level aspects of a 'common language', jokes and other forms of communication, both formal and informal, help to build intersubjective understanding without formal structures. Strong social capital through the creative process helped the AHs to monitor and re-iterate inter-subjective 
understanding in order to maintain (and strengthen) group climate and facilitate the mobilization of the groups' knowledge resources over time.

As Rosness (2004:105) states: 'the way a group goes about building intersubjective understanding may be strongly related to group climate and to the mobilization of the knowledge resource of the group members.' Such mobilization might also be influenced by workplace design. Gjersvik and Blakstad (2004) highlighted how workplace design and development can be matched with certain 'archetypes of knowledge work', which are seen as boundary objects facilitating dialogue amongst individuals. In MA the workplace design (or setting) itself facilitated different degrees of exploitive and explorative learning. The office design encouraged AHs to meet the Creatives in an informal setting for their briefings (eg sofas and soft chairs rather than a formal meeting room) in an attempt to maximise social capital. This provides a good example of the interaction between structural and social capital.

Once the Creatives have been briefed, their human capital becomes key: they need to know what questions to ask and to be able to spot any problems which might occur with the execution of the brief. If they find any serious gaps in the Creative Brief then the AHs may have to go back to the client to clarify details. The nature of the social capital and especially the personal working relationships between the AHs and the Creatives, will be vital to knowledge flow. We observed some variation: some AHs seemed to work very hard on developing social capital and ran their briefing and debriefing meetings very informally, others took a much more formal role. Here, the nature of the client and the character of the client demands influenced the approach adopted and emphasis placed on exploitive and exploratory learning. Accounts where work was piecemeal or paid on a price-per-piece basis applied far more formal structures and short-term, exploitive knowledge to the creative process compared with accounts on retainers, responsible for managing longer-term campaigns, which adopted a much more informal approach, integrating explorative learning into their time horizons.

The process of joint learning continues as the Creatives go away to work up some ideas which they then present to the AHs. The AHs will give an initial opinion - they might ask the Creatives to work more on their ideas or they will take the proposals to 
the client. A series of interactions then begins between the client representatives, the AHs and the Creatives as ideas, comments and knowledge are passed backwards and forwards. The AHs effectively act as the 'go betweens' or 'buffers' between the client and the Creatives. However, this is not simply a communications activity because the AHs are often translating and interpreting the requests of the client. There is clear evidence from our observations that the creation of intellectual capital is facilitated by the presence of strong social capital (Subramaniam and Youndt, 2005).

The role of the leading $\mathrm{AH}$ is very important in promoting learning within such interdisciplinary action teams because of the power they hold over the actions of individuals within the creative process. After all, organizational power structures play an influential role in mediating the balance between exploitive and exploratory learning (Clegg, 1999; Vickers, 2000). Edmondson (2003) argues that in interdisciplinary action teams, containing, by definition, individuals with diverse, specialised skills, improvisation and coordination of action requires such a level of openness that distinctions of status, training, as well as inter-subjective understanding can be overcome. This is important in an organization like MA that has to rapidly respond to client demands or has short-term frames within which considerable creative energy has to be brought to the surface.

In this respect, MA appears to be very successful. There is a demonstrable ability and willingness by the AHs and the Creatives to contribute and receive evaluations, criticisms and suggestions on the work being discussed. Both the Creatives and the AHs bring ideas forward to develop the intellectual capital, and the Creatives are willing to accept this. This is especially important, as Alvesson (1994) has noted when the client is giving feedback on creative proposals. The Creatives may be very sensitive to comments on their intellectual capital and care will be needed when the AHs give feedback to them. Great skill is needed here to balance the needs of the client with the sensitivities of the Creatives. The Creatives will often take great pride in the intellectual output and may interpret a criticism of their work as a criticism of them personally. Unless social capital is very strong there is a danger that relations will break down, especially when the demands of the client are high and the time available is short. 
In the words of one Account Manager, 'By the time we get to the debrief their ideas are on the line - so we see this as a time to share the feedback...it's up to us to communicate the comments of the client accurately - if we can do that then there is a better chance that the Creatives will solve the problem.' Some Account Managers created a written debrief document, however as one said 'this is not simply issued to the Creatives, instead, it is used as a starting point for discussion. It is not a closed argument. The Creatives may modify what they've done or they will come back to the client with suggestions. It's ok with this client, because they are flexible but they are not all like this, some have a set way of doing things.' There may be several iterations of idea generation, for instance as one Account Manager said, 'the graphic was not quirky enough and they asked us to push it further to change the visuals. So we came up with something else, and they said it was too indirect - so we need something in between. It's not quite there yet.'

Over time as a result of these interactions both the Creatives and AHs in MA begin to improve their knowledge of the client and its products substantially; they are developing client capital. As the campaigns proceed they are building up their stock of client specific knowledge to the extent that the balance of human capital shifts. Both the AHs and the Creatives are beginning to draw on their previous experience with the client, according to one Account Manager, 'on the (client) account we are learning as an account team, there's lots of new stuff.' After a period the client will realise that MA staff know more about their product than they do. In fact they expect this and some will prefer this, after all the reason for appointing MA was to draw on their expertise and knowledge. Creatives, for example, learn how to write appropriate copy instinctively and the designers adopt the brand style. The AHs build up more confidence about what they think the client will or will not accept and they will communicate this to the Creatives. AHs are not only building up their human capital, they are also developing their client capital, especially in terms of the relationships they are developing with the client representatives which may become very personalised. One Account Manager said, 'after a while you get to know the account, you know what they want before they ask.' If their organizational learning processes are sufficiently effective this knowledge of the client becomes a source of competitive advantage and helps MA to retain its clients (indeed up until now it has a very 
impressive record of client retention - it has lost no clients in its existence). They create a dependency by the client on them.

The process of creating intellectual capital is also facilitated by the development of social and structural capital within the account team. Members of the account get used to working with one another and build up norms and behaviours which are effective. The AHs learn whether they can trust the Creatives to produce work on time and how they can get the best from them. The Creatives learn how to interpret the feedback from the AHs, pick out the priorities and the key deadlines. Growing social capital is often indicated in their interactions by the use of humour, shared jokes and long running stories, which often refer to non-work social activities.

At the start of a project the client may look for MA to exploit its existing track record and expertise with relatively little exploratory work. Indeed, one of the reasons MA wins so many accounts (their pitching success rate was claimed to be $80 \%$ ) is through their demonstrable expertise in certain areas and successful track record in knowing how particular campaigns and mechanisms can be exploited. In some aspects of their work the client wants MA to use previous work, such as exploiting their knowledge of the drinks industry and applying it to a different product like mobile phones. According to one Account Manager 'we know what will work and what will not, for example if you want to communicate simple ideas to a mass audience you need humour and plays on words.' However, learning is still taking place, 'Although we have a good insight into the brand based on the work we have done and our research, there's still lots of detail we don't have - we are learning - we don't know the intricacies. We are working with the client, they want us to challenge them, they are learning from us, they can teach us and we can teach them.'

As the relationship with the client develops and experience and social capital are built up it becomes easier to produce the 'safe' work more quickly. Attention then moves to producing exploratory work: the innovative, highly creative work that the client was seeking. This work would be shown to the client as examples of their ability to explore new ideas, even though they might be rejected, perhaps because they were too far away from the existing tone and content of the client's promotions and advertising. In the words of one Account Manager, 'we have to keep showing them the love.' 
The mix between exploratory and exploitive learning varies between different clients and between campaigns for the same client and within the same campaign. For example according to one Account Manager, 'the client is a difficult account to work on, its advertising has been consistent for the last 50 years. We have to follow the client policy of tell and sell.' Differences in the interactions between structural and social capital mean that the mix of bilateral learning varies between clients. Campaigns for some clients will be based virtually completely on exploiting their existing knowledge. Other campaigns, perhaps for different clients or at different relationship stages, will be much more adventurous where the client is looking for new ideas and innovation. The management of the creative process also varies depending on the style adopted by the AHs which is not always related to the wishes of the client. Some AHs will stimulate innovation and creativity in their dealings with the Creatives asking for and contributing ideas and providing constructive feedback. Other AHs adopt a much more controlling style, closing down debate, stifling creativity and reducing exploratory learning opportunities ${ }^{5}$.

\section{Delivery of the service or product}

The output of this creative process will take a number of forms ranging from a formal presentation on the client's premises to an email followed up by a brief telephone conversation. Working hours leading up to delivery will often be long, commonly involving late nights and weekends. One of the key promises of MA, to 'over deliver' (to produce more and better materials than required to as part of the original brief), puts even more pressure on both the account handlers and the Creative staff. The delivery of the final product may be dependent on suppliers of services such as printers, although by this time the major creative input is complete. Typically, the work on a campaign will be part of a bigger contract that MA has with the client. For example some point of sale material may be delivered for one campaign and the work then moves on to the next promotional campaign. As we know both AHs and creative staff are working on a whole series of projects simultaneously so the end of one project will not lead in a linear fashion to the start of another project. Much more likely staff will simply switch their attention from one project to another depending on their, and their managers', judgement of priorities.

\footnotetext{
${ }^{5}$ This may, of course, be a response to the client's style and preferences.
} 


\section{Accelerated/shorter-term process: responding to the client}

Our discussion above fails to capture the sheer unpredictability and fast changing nature of MA's business. Although there are plenty of campaigns that do fit the stages identified above, there are others where the process is accelerated or stages are missed out completely, usually because the client is in a hurry. MA prides itself on its responsiveness to this kind of client request, especially if they are longstanding clients or clients whom they are anxious to retain, fearful that another agency will take their place if they turn the business away.

The first stage of winning the business may be truncated so the request is made by phone asking for some work to be done urgently. This may be because of a change in a wider marketing campaign, the actions of a competitor or perhaps a product recall. Activities that might normally take three weeks may be condensed into for example a few days or even hours. A team will be brought together at short notice and a Creative Brief agreed on the phone and email without a face-to-face meeting with the client. Creative ideas including both art work and copy will be sent to the client via email with feedback given over the phone with the final version agreed again without a physical meeting. These short term accelerated projects are of course taking place alongside the other campaigns and projects producing along the normal timescale. This kind of 'call to action' work places great strain on the firm's resources, but is the kind of work which MA grew up on and contributed significantly to its success and fast growth.

This is very much a consequence of the reactive element that is included in most marketing campaigns. Clients will be influenced by both the market and actions of competitors. They will want to avoid their rivals from gaining an advantage over them in the short term and therefore, at times, they will wish to move very quickly. A successful marketing campaign by a competitor may stimulate a client to want to launch something similar. A change in the market, for example the outcome of a major sporting event, or an chance to advertise somewhere which is normally unavailable will prompt the client to want to take advantage of the opportunity. This in turn puts pressure on MA. In many ways the client is transferring its own market conditions to the agency. 
Often the client will trade heavily on its social capital, using their personal relationships to persuade the AHs to take on the work, perhaps allied with an implicit competitive threat that they could take the work elsewhere. Social capital between the AHs and Creatives will also be sorely tested especially when there are competing demands on their time. This may lead to disputes over the allocation of resources which are only resolved through the structural capital of the firm by the AHs and the Creatives seeking the assistance of their respective bosses. The work here tends to be exploitive because the need to respond quickly to client requests gives little opportunity for exploratory learning.

One Account Director described a particularly fraught situation when he was asked to respond to a client request at very short notice: 'I have told the client that we will come back with only one concept and there will be only one execution because of lack of time. The client knows what to expect - we're managing their expectations everyone knows it's going to be rushed.'

Human capital, especially of the Creatives is under severe pressure. Often they have to respond to a client's request at very short notice, when they have other competing demands on their time. Compromises are often involved - they may seek to bargain with the AHs to explain what they believe is possible or not. Their possession of distinctive competence, especially when allied to a proven track record often gives them power when dealing with the AHs. The AHs, on the other hand, derive their power from their client capital in terms of knowledge of what the client will accept by what deadline and their, usually good, social relations with the client. An element of shadow boxing occurs here as none of the parties (the client, the AHs or the clients) know the true situation over what is, or is not, possible. Yet, despite its problems it is often this kind of work which pleases the client. A small piece of work for a new client done at short notice may lead to further work; work done at short notice for an existing client will further cement the relationship. MA has built a reputation not only for the high quality of its work but its willingness to deliver at very short notice. However, one of the issues it faces is whether it can continue to behave in this way as it grows in size (Tushman and O’Reilly III, 1996; 2004). 


\section{Discussion}

This case illustrates two temporal frames within which combinations of exploratory and exploitive learning take place. This is a critical dimension of our case analysis because time is seen as a fundamental but neglected variable in organizational analysis (Butler, 1995:925) and it impacts directly on how we view learning in organizations (Bergson, 1992). The account management process assumes that organizational learning takes place within a predictable or longer-term time frame through a series of managed stages. Organizational learning in the second time frame is much more accelerated where knowledge flows in a concentrated period often emphasising exploiting existing knowledge because time is short. Not only does MA have to combine these two forms of learning but it has to do so quickly because staff are working on multiple projects simultaneously involving groups both inside and outside the organization.

The juxtaposition of the two modes of learning (explore and exploit) together with the two time frames (accelerated and planned) identified in the case study allows us to develop a model of four learning orientations that are situated within the case organization (see Figure 2). An appreciation of the simultaneity (Chai, 2002) of both the modes of learning and the time frames within which the learning occurs provides us with a more realistic account of the strategic renewal processes in our case study. We move beyond the linear notions of learning to a grounded dynamic theoretical framework.

In the fast paced environment of the knowledge intensive firm there is seldom the luxury to select either an explorative or an exploitive learning mode which comfortably spans the Creative Briefing process. Such an approach to learning would be far too risky for both the firm and their clients. The dominant practice is a continuous switch between developing new knowledge and refining existing knowledge within one client team at one moment in time. Furthermore, the Creative Briefing process (which frames organizational learning) continually needs to be adapted and shaped: at times it plays out stage after stage but often it needs to be malleable to fit around client, human and organizational capital capacity. 
Drawing on existing solutions (exploit/accelerated):

This learning orientation exists within the accelerated time frame and is predominantly exploitive in its learning mode. In several of the client teams we observed a reliance on highly skilled human capital, which when combined with strong social and client capital led to the need or indeed the desirability to draw on existing solutions. Here the teams, when faced with tremendous client pressure, had to shape the key client interface processes in order to deliver solutions which 'worked in the past'. For example there were some examples of accelerated learning on one account producing promotional materials for a mobile phone company which was normally planned and exploitive. Occasionally, the client would ask for work to be done at very short notice to meet the deadline for the launch of a new promotional offer made in response to competitors' actions. This might involve making small changes to the art work on existing posters used in store. As the AH commented, 'we say to the client that the minimum time is three days, but sometimes it's within one day. We have to work to printers' deadlines for the materials to go instore.' In these circumstances it was the client which drove this approach of making small changes to tried and tested solutions. This illustrates the importance of client capital within this learning orientation.

\section{Creative combination (explore/accelerated)}

The increased client pressure to deliver solutions at a fast pace was sometimes combined with the need for new or fresh solutions. This was also seen as important to the development of the knowledge and experience of the AHs and the Creatives. As one Group Account Director said, 'we often get the best from our Creatives when we are under pressure. If you give them too much time to think you don't get such a good result.' The flows of knowledge developed across a different pattern in this learning orientation. Deep technical expertise (human capital) was often combined with newer relationships within the firm (social capital) and with the client (client capital) to create new knowledge which was embedded in the client solution. Working across relational boundaries was important to the renewal of knowledge assets in compressed time frames. For example, one AH was asked by his client (a TV channel) to produce a two page advertisement for a prestigious trade magazine within a week. He said, 'I'm annoyed with the client that they've asked us to do this. I'm trying to educate the client. We're doing them a big favour if we pull it off. But the relationships with 
the Creatives can take a dive, they'll say 'we can't do it', The team have to work within deadlines which are specified quite tightly by the client, for example in terms of colours they can use. According to the AH, 'About 50\% of this is adapting what we already have and the other half is creative.'

\section{Expert solutions (exploit/planned)}

In terms of managing risk this represented the 'safest' learning orientation for our case firm. Here the creative briefing process could be followed through with few minor changes and adjustments and there was a heavy reliance on existing knowledge stocks. Hence, this orientation was the most stable of the four. Our data showed that deep technical expertise (human capital) was combined with long standing client and team relationships (social and client capital) across the creative briefing process (organizational capital). The focus of this learning orientation was to refine existing knowledge stocks thereby tying the client in to the continued offering of expert solutions. Only minor adjustments were made in the offering of the final solution. For example, the mobile phone client had fixed templates for their point of sale materials which allowed for small changes to be made monthly as part of a quarterly marketing plan. The formal Creative Briefing process was dispensed with as around 20 items per month were handled by a small team of 3 AHs and 5 Creatives. Posters and flyers were frequently modified by small changes to the graphics and layout to heighten their impact as new campaigns and products were offered to the market.

\section{$\underline{\text { Renewal (explore/planned) }}$}

Within this learning orientation MA worked closely with the client to develop new knowledge stocks. For the majority of the time the client briefing process could be followed but the aim of the process was to arrive at new solutions or offerings. For example, one alcoholic drink client awarded MA the contract because they wanted them to create a completely new look and feel to the brand using an integrated marketing campaign, This involved challenging and changing the existing brand images and promotional devices. Planning the campaigns for this took place over a year ahead with big promotional events tied to key dates associated with the brand. This long term plan was needed to allow time for the physical production and distribution of the promotional materials to the hundreds of retail outlets involved. In this orientation the client is heavily involved in the shaping of new strategic 
knowledge and therefore invests time through in MA's renewal processes. This orientation was also the most desirable in building strategic knowledge assets that could be relied upon in the future.

MA has presence in all four quadrants of the matrix demonstrating its ability to practice bilateral learning in both time frames. It has been successful in building valuable intellectual capital because it has been able to leverage key forms of capital at the right time and pace to meet the diverse needs of their clients. As the Creative Director said, 'Our working model is about variety which is really important. People are attracted by that, and when they apply to us they say I've working for X on Y for two years. That does not happen here'.'

The relationships between interdisciplinary teams allied to the highly appropriate human capital has produced a combination of exploitive and exploratory learning which is well suited to the fast moving, uncertain environment (Crossan et al, 1989; March, 1991; Edmondson, 2003; Kang and Snell, 2004). Effective social control systems, strengthened by long standing management, have enabled individuals to pursue bilateral learning (Kang and Snell, 2004) without the need for structural ambidexterity (Birkinshaw and Gibson, 2004). As Subramaniam and Youndt (2005) argue elsewhere, strong social capital has been vital in combining with organizational and human capital to produce incremental and radical innovative capabilities respectively.

Critically, MA has managed the trade-off between short-term profitability and longterm growth and success, which are key to ambidextrous organizations that must bring about and cope with both incremental and revolutionary change (Tushman and O’Reilly III, 1996, 2004). Central to this has been its ability to leverage strong social capital (Nahapiet and Ghoshal, 1998), complemented by appropriate power structures (Clegg, 1999; Vickers, 2000) and ambidextrous leaders who have been able to maintain an effective social control system (Tushman and O’Reilly III, 1996). This has helped in a number of ways. 


\section{Conclusion and Implications}

The importance of the speed of response demonstrated in this case has a number of implications for practice and for theory. Perhaps the most important practical implication is that firms operating in this kind of environment need to develop knowledge stocks and flows which allow them to respond quickly to the actions of their clients and their competitors.

The need to combine exploratory and exploitive learning and be able to switch between these two modes very quickly creates various problems because of the supporting infrastructure associated with these two modes of learning. Exploratory learning is promoted by a varied expertise in a broad human capital base, flexible processes and structures and diverse, loosely coupled, entrepreneurial internal and external structures. Exploitive learning is facilitated by specialists working with clear, formalised procedures in tightly coupled, mutually dependent relationships. The need to combine these often at short notice creates various tensions for the employees and the firm.

Employees will be faced with simultaneous conflicting demands for short term routine repetitive work and longer original innovative work. They will need to be able to switch between these two modes of learning and working almost instantly making the normal pressures of working in this environment even more intense. This may reduce the quality of their working life and increase employee turnover. From the managerial viewpoint the structures, policies and procedures will need to be designed develop and support the appropriate forms of human capital and knowledge flows. Strategically the firm needs to strike a balance between reactive exploitive learning and more planned exploratory learning. Too much reliance on short term work could weaken the capacity for bigger, longer term projects. Committing resources to the longer term work might reduce the ability to respond quickly to clients' requests. Indeed the growth of the firm might encourage a movement away from the reactive process which was the basis for the early success.

MA is showing the signs of the classic growth problems these kinds of PSFs face; Tushman and O’Reilly III’s (1996) ‘success syndrome’. Firms of this type are often set up by entrepreneurs who are anxious to run their business in the image of their 
beliefs which are often a negative response to their experience of big business. It is these beliefs as well as their specific competence which are often part of their appeal to both clients and employees (Alvesson, 1994:556). In their early stages they have limited hierarchy and bureaucracy with decentralised decision-making and selforganised teams (Newell et al., 2002). This kind of approach works well if the values are strong and consistent enough (Tushman and O’Reilly III, 1996; Rasmussen, 2004). However, as the firm grows in size their approach taken becomes unsustainable - the informal practices simply will not stretch to that size and they risk diluting their knowledge intensity and advantageous, esoteric characteristics (Starbuck, 1992) ${ }^{6}$.

MA has demonstrated that not only do firms of this kind have to be ambidextrous they also need to be able to operate at two different learning speeds and be able to switch between them. This has various theoretical implications. In particular this illustrates the critical interactions between the forms of capital the types of organizational learning required to generate these forms of knowledge and the systems needed to support these learning processes. This poses questions, following Subramaniam and Youndt (2005), about what kinds of organizational learning are produced by the interactions between particular forms of capital. Put simply we need to understand how knowledge stocks and knowledge flows interact to create the most appropriate forms of organizational learning. We must also take account of the time dimension, especially the speed of knowledge flow, if we are to analyse the intellectual capital creation process in this kind of fast moving firm. This focus on temporal frames and the knowledge-based perspective on organisational learning have potentially interesting implications for the organisational capabilities literature, which has traditionally struggled to combine the explorative (flexible, evolutionary) and exploitative (efficient, routine-based) aspects of capability building. This poses a fruitful avenue for future research.

\footnotetext{
${ }^{\mathbf{6}}$ This raises a whole series about the appropriate HR systems which we do not have time to discuss here.
} 


\section{References}

Alder, P.S., Goldoftas, B. and Levine, D. (1999) Flexibility versus efficiency? A case study of model changeovers in the Toyota production system, Organization Science, 10, 43-68.

Alvesson, M. (1994) Talking in Organizations: Managing identity and Impressions in an Advertising Agency, Organization Studies, 15:4, 535-563.

Alvesson, M. (2000) Social identity and the problem of loyalty in knowledge intensive companies. Journal of Management Studies, 37:8, 1101 - 1123.

Alvesson, M. (2004) Knowledge Work and Knowledge-Intensive Firms: Oxford: Oxford University Press.

Antonacopoulou, E and Tsoukas, H. (2002) Time and reflexivity in organization studies: an introduction. Organization Studies, 23(6), 857-62

Benner, M.J. and Tushman, M.L. (2003) Exploitation, exploration, and process management: The productivity dilemma revisited, Academy of Management Review, 28, 238-256.

Birkinshaw, J. and Gibson, C. (2004) Building ambidexterity into an organization, MIT Sloan Management Review, 45:4, 47-55.

Brown, S.L. and Eisenhardt, K.M. (1997) The art of continuous change: Linking complexity theory and time-paced evolution in relentlessly shifting organizations, Administrative Science Quarterly, 42, 1-34.

Butler, R. (1995) Time in organization studies: Its experience, explanations and effects. Organization Studies, 16 (6): 925-950

Chai, R. (2002) Tim, duration and simultaneity: rethinking process and change in organization analysis. Organization Studies, 23(6), 863-868

Clark, P. A. (1985) A review of the theories of time and structure for organizational sociology. In Research in the sociology of organizations. S.B. Bacharach and S.M. Mitchell (eds), 35-80.

Clegg, S. (1999) Globalizing the intelligent organization: Learning organizations, smart workers, (not so) clever countries and the sociological imagination, Management Learning, 30:3, 259 - 280.

Crossan, M.M., Lane, H.W., \& White, R.E. (1999) An organizational learning framework: from intuition to institution. Academy of Management Review, 24:3, 522-532. 
Edmondson, A.C. (2002) The local and variegated nature of learning in organizations: A group-level perspective, Organization Science, 13, 128-146.

Edmondson, A.C. (2003) Speaking up in the operating room: how team leaders promote learning in interdisciplinary action teams, Journal of Management Studies, 40:6, 1419 - 1452.

Evans, P., Pucik, V. and Barsoux, J-L. (2002) The Global Change: Frameworks for International Human Resource Management. New York: McGraw-Hill.

Gibson, C. and Birkinshaw, J. (2004) The antecedents, consequences, and mediating role of organizational ambidexterity, Academy of Management Journal, 47(2), 209-226.

Gjersvik, R. and Blakstad, S.H. (2004) Designing knowledge work space: archetypes of professional service work as tool for change. In, A. Carlsen, R. Klev and G. von Krogh. Living Knowledge: The Dynamics of Professional Service Work: Basingstoke: Palgrave Macmillan: 140 - 163.

Ghosal, S. and Bartlett, C.A. (1997) The Individualized Corporation: A Fundamentally New Approach to Management: New York: Harper Business.

Hay, R.H. and Pisano, G.P. (1994) Beyond world class: The new manufacturing strategy, Harvard Business Review, 72(1): 77-86.

He, Z-L. and Wong, P-K. (2004) Exploration vs. exploitation: An empirical test of the ambidexterity hypothesis, Organization Science, 15:4, 481 - 484.

Kang, S.C. and Snell, S. (2004) Managing intellectual and capital architectures: HRM and bilateral learning in law firms.

Kinnie. N. and Parsons, J., (2004) Managing Client, Employee and Customer Relations: Constrained Strategic Choices in the Management of Human Resources in a Commercial Call Centre in Deery, S. and Kinnie, N. (2004) Call Centres and Human Resource Management, Basingstoke: Palgrave Macmillan.

March, J.G. (1991) Exploration and exploitation in organizational learning, Organization Science, 2:1, 71-87.

Mintzberg, H. (1979) Structures in Fives, Designing Effective Organizations: Englewood Cliffs, NJ: Prentice Hall.

Moss Kanter, R. (1989) When giants learn to dance: Mastering the challenges of strategy, management and careers in the 1990s. New York: Simon \& Schuster.

Morris, S. and Snell, S. (2006) (2006) Assessing the Relationship between Knowledge Stocks and Flows: A Value Proposition for Professional Service 
Firms part of the Symposium Strategic Renewal and Value Creation in High Intellectual Capital Firms, Academy of Management Meeting, Atlanta, 2006.

Morris, T. (2000) Promotion policies and knowledge bases in the professional services firm. In, M. Peiperl, M. Arthur, R. Goffee and T. Morris (eds). Career Frontiers: Oxford: Oxford University Press: 138 - 152.

Nahapiet, J. and Ghoshal, S. (1998) Social capital, intellectual capital, and the organizational advantage, Academy of Management Review, 23:2, 242 - 266.

Newell, S., Robertson, M., Scarbrough, H. \& Swan, J. (2002) Managing Knowledge Work: Basingstoke: Palgrave Macmillan.

Nonaka, I. and Takeuch, H. (1995) The Knowledge Creating Company: How Japanese Companies Create the Dynamics of Innovation. New York: Oxford University Press.

Rasmussen, B. (2004) Organizing knowledge work(ers): the production of commitment in flexible organizations. In, A. Carlsen, R. Klev and G. von Krogh. Living Knowledge: The Dynamics of Professional Service Work: Basingstoke: Palgrave Macmillan: 67 - 88.

Rosness, R. (2004) 'I think I understand what you mean': negotiating intersubjective understanding’ in, A. Carlsen, R. Klev and G. von Krogh. Living Knowledge: The Dynamics of Professional Service Work: Basingstoke: Palgrave Macmillan: $99-114$.

Schein, E. (1983) The role of the founder in creating organizational culture, Organizational Dynamics, Summer: 13 - 28.

Schien, E. (1992) Organizational Culture and Leadership, $2^{\text {nd }}$ ed: San Francisco, CA: Jossey Bass.

Starbuck, W. (1992) Learning by knowledge-intensive firms, Journal of Management Studies, 29:6, $713-740$.

Stata, R. (1989) Organizational learning: The key to management innovation. Sloan Management Review. Spring: 63-74

Subramaniam, M. and Youndt, M.A. (2005) The influence of intellectual capital on the types of innovative capabilities, Academy of Management Journal, 48:3, 450 $-463$.

Swart, J. (2004) Identifying the sub-components of intellectual capital: a literature review and development of measures, University of Bath Working Paper Series. 
Swart, J., Kinnie, N. and Purcell, J. (2003) People and Performance in Knowledge Intensive Firms, London: Chartered Institute of Personnel and Development.

Swart, J. and Kinnie, N.J. (2004) Managing the Careers of Professional Knowledge Workers, London: Chartered Institute of Personnel and Development.

Tushman, M.L. and O’Reilly III, C.A. (1996) Ambidextrous organizations: managing evolutionary and revolutionary change, California Management Review, 38:4, 8 $-30$.

Tushman, M.L. and O’Reilly III, C.A. (2004) The ambidextrous organization, Harvard Business Review, 82:4, $74-81$.

Vickers, M. (2000) Clever versus intelligent organizations: cases from Australia, Academy of Management Executive, 14:3, 135 - 136.

Woolgar, S. (1988) Knowledge and reflexivity: New frontiers in te sociology of knowledge. London: Sage

Youndt, M.A., Subramaniam, M., and Snell, S.A. (2004) Intellectual capital profiles: an examination of investment and returns, Journal of Management Studies, 41:2, $335-361$. 
Figure 1: Combining Forms of Capital

(Swart, 2004)

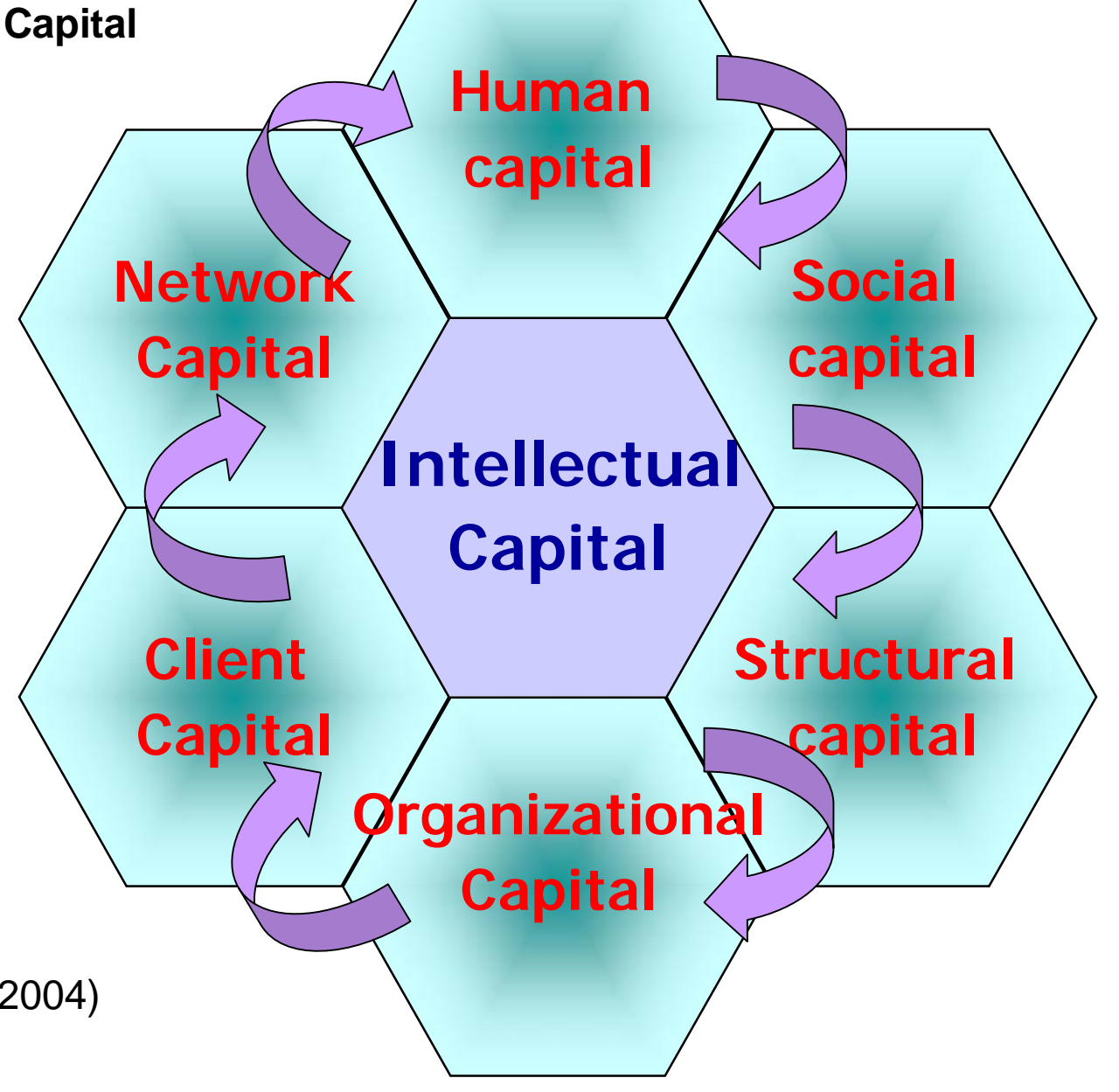


Figure 2

\section{Learning orientations: simultaneity of modes and time-frames}

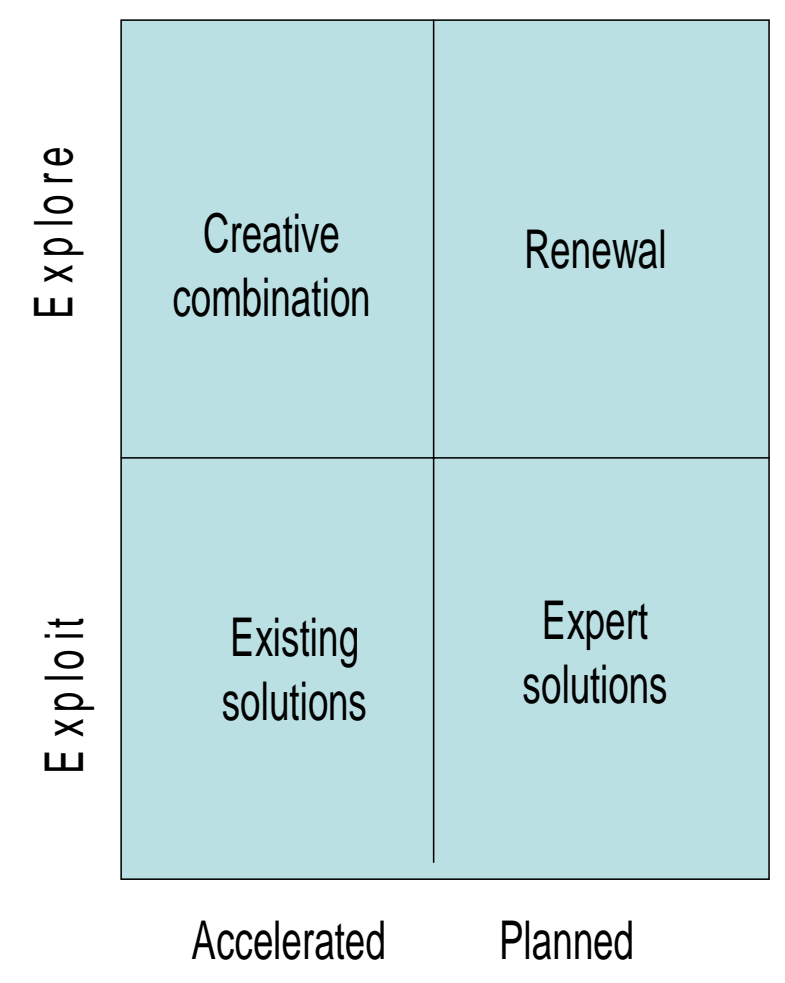


Table 1: Stages in the Process of Organizational Learning

\begin{tabular}{|c|c|c|c|c|}
\hline $\begin{array}{l}\text { Organizational Learning } \\
\text { stages }\end{array}$ & Winning the Business & Establishing the Account & Working with the Client & Delivery \\
\hline Learning Processes & $\begin{array}{l}\text { o Clients attracted by } \\
\text { possibility of exploiting } \\
\text { existing knowledge } \\
\text { o Exploratory learning } \\
\text { from original research }\end{array}$ & $\begin{array}{l}\text { o Exploring by learning } \\
\text { from the client - feedback } \\
\text { from pitch } \\
\text { o Close working between } \\
\text { groups inside and outside } \\
\text { the organization }\end{array}$ & $\begin{array}{l}\text { o Exploiting becomes } \\
\text { easier so exploring } \\
\text { becomes more important } \\
\text { o Close working between } \\
\text { groups inside and outside } \\
\text { the organization }\end{array}$ & $\begin{array}{l}\text { o Mix of exploratory and } \\
\text { exploitive learning }\end{array}$ \\
\hline $\begin{array}{l}\text { Stocks and flows of } \\
\text { knowledge }\end{array}$ & $\begin{array}{l}\text { o Emphasis on human } \\
\text { capital especially } \\
\text { creativity, selling skills } \\
\text { and social capital } \\
\text { o Structural capital vital } \\
\text { for bid team formation and } \\
\text { knowledge flows }\end{array}$ & $\begin{array}{l}\text { o Client human capital } \\
\text { dominates knowledge } \\
\text { flow, developing agency } \\
\text { human and social capital } \\
\text { structural capital is } \\
\text { important for team } \\
\text { formation and relations } \\
\text { with the client }\end{array}$ & $\begin{array}{l}\text { o Interaction between } \\
\text { human and social capital is } \\
\text { key to knowledge flow } \\
\text { o Organizational capital } \\
\text { is key to the creative } \\
\text { process } \\
\text { o Human, client and } \\
\text { social capital develops to } \\
\text { surpass the client } \\
\text { knowledge }\end{array}$ & $\begin{array}{l}\text { o High stress on human, } \\
\text { social, structural and } \\
\text { organizational capital } \\
\text { o Disputes over priorities } \\
\text { are likely when time and } \\
\text { resources compete }\end{array}$ \\
\hline
\end{tabular}

